\title{
Direito Para o Nosso Tempo
}

IGOR TENÓRIO

Professor da Universidade de Brasília. Assistente Jurídico do Ministério da Agricultura

A invasão da área jurídica como resultante da revolução tecnológica já começou no Brasil, e embora seja um processo ainda em embrião, relaciona-se aos valôres fundamentais de que cuida o cultor do Direito, e a análise do mesmo é condição essencial à atualização de nosso conhecimento sôbre o papel do advogado, na sociedade da próxima década.

Não se cogita, aqui, de necessidade de que advogados se tornem também bons engenheiros; nem por igual, imaginase hipótese de aplicação eletrônica do Direito, em sentença ditada por uma máquina.

Apenas, ocorre no Brasil que cérebros eletrônicos estão sendo aplicados, e cada vez mais, em atividades direta ou indiretamente ligadas ao interêsse do advogado, do legislador, do juiz, do assessor jurídico ou professor de Direito.

E se as máquinas se tornaram essenciais, desde as operações de fiscalização tributária, ao contrôle de registros de trầnsito, à administração de justiça e até para fins mais amplos, no campo do ensino e da informação legislativa, então chegou a hora de conhecermos a Cibernética.

Devemos valer-nos das facilidades que ela oferece em relação à consulta à legislação e à jurisprudência. Por igual, teremos de nos habilitar a responder, com inteligência e conhecimento de causa, aos problemas criados e aos que surgirão, com a crescente aplicação da tecnologia dos computadores em relação ao nosso sistema de vida.

Afinal de contas, que é a Cibernética?

É uma ciência que resulta da aplicação analógica entre organismos vivos e a máquina. Integrou conhecimentos científicos de variadíssimas áreas. E ocupa-se "de investigação de sistemas de natureza arbitrária capazes de perceber, armaze- 
nar e transformar informação, utilizando-a para fins de contrôle e regulagem".

É uma palavra de sucesso mundial, para batizar um conjunto de teorias de física, matemática, a que se juntaram parcelas de temas retirados à psicologia, à fisiologia, à psiquiatria e à sociologia, no comêço da engenhosa formulação teórica de Norbert Wiener e seus colaboradores; e que, atualmente, conta com achegos de quase tôdas as facêtas do saber humano.

Partindo dessas premissas, a tecnologia já construiu máquinas automáticas de crescente complexidade e perfeição, e cujo emprêgo generalizado em numerosíssimos campos de atividade, está provocando uma verdadeira reformulação de conceitos técnicos, sociais, econômicos e até humanos.

Louis Couffignal (In a Cibernética, Difusão Européia do Livro, 1966, pág. 95), resumiu o impacto da Cibernética, dizendo que esta mecanizou funções mentais, e permitiu que máquinas pudessem executar, pràticamente, qualquer trabalho humano.

Daí, as conseqüências que desencadeou, sob os pontos de vista técnico, financeiro, humano e social.

Serviços executados com maior precisão e redução de custos salariais; seriação de tarefas; melhor aproveitamento de pessoal altamente qualificado, além de mais perspectiva de redução das jornadas de trabalho e de considerável aumento da produtividade e da riqueza geral - eis o lado simpático da Cibernética. Porém, vêm as questões correlatas de desemprêgo ou de maior lazer; necessidade de investimentos em equipamentos dispendiosos e quase fora de alcance dos paises em vias de desenvolvimento; e os efeitos sociais da automação, talvez obrigando a elaboração de planos nacionais, quanto ao seu emprêgo, levando-nos a lembrar o brado da Associação Internacional de Cibernética, em 1957: - A AUTOMAÇÃO NÃO DEVE DESENVOLVER-SE NA ANARQUIA!

Por isso mesmo é que na alvorada da utilização da conquista da Cibernética no Brasil, cumpre convocar-se o profissional do Direito, para que, ao lado do economista, do engenheiro, do sociólogo, do dirigente industrial, do operário, possa participar dos estudos, dos debates e da formulação de uma legislação que virá a seu tempo, mas que deve estar a caminho nesta década, para a preservação dos objetos necessários e dos princípios cristãos de nossa civilização, contra 
o perigo de desumanização da economia pela onipotência da máquina.

Por que se pode aplicar o computador em áreas de profissões legais?

Em certo sentido, o direito positivo se compõe de sistema lógico, com o fito de disciplinar a vida social.

Miranda Rosa (In Sociologia do Direito, Zahar Editôres, 1970, pág. 32), ao falar de fenômeno do Direito, e ao mostrar as diversas faces pelas quais pode ser observado pela Filosofia do Direito e pela Sociologia Jurídica, acrescenta:

"Também pode ser encarado em têrmos adequados à atividade profissional dos juristas, como um conjunto sistemático de normas de conduta, guardando lógica interna e de natureza dogmática; encontramos, sob êsse aspecto, a ciência dogmático-normativa do Direito".

O Direito, como norma, é um conjunto de princípios coerentes entre si, obedecendo a uma lógica formal e dogmática. Como norma, visa ao contrôle da Sociedade.

Como conjunto de princípios lógicos se sujeita a uma descrição matemática. Por ambas as razões, pode ser objeto de tratamento cibernético.

Em conseqüência, no prefácio do livro COMPUTADORES E O DIREITO (Computer \& the Law), editado pela Associação dos Advogados Americanos (American Bar Association), está mencionado que o principal emprêgo de maquinaria de computação é a recuperação de informações em matéria legal: - leis, procedimentos administrativos e opiniões judiciais.

Como os advogados são, ao mesmo tempo, profissionais que através do exercício de seu ofício beneficiam seus concidadãos e dêle se servem como frente de ganho para uma existência condigna, e como atuam em campos diversos como negócios privados e assessoria aos governos, devem acompanhar o desenvolvimento em qualquer ramo do progresso humano.

E assim precisam inteirar-se do emprêgo do processamento de dados, nas fases da pesquisa de leis e publicações, declarações fiscais, administração de justiça, processo legislativo, justiça criminal, registros públicos etc.

Não é nosso propósito traduzir textos ou expor experiências já executadas no exterior, nem citar, neste ensejo, aspec- 
tos mais visiveis e de certo modo emocionantes do emprêgo do computador em relação à área legal, desde que tivéssemos de valer-nos de autores, fatos e informações fora da experiência brasileira.

Porém, já há material suficiente a êsse objetivo, colhido em nosso país.

O Brasil ingressou, legalmente, na era do computador, com a lei 4.516 , de 1 o de dezembro de 1964 , que criou o Serviço Federal de Processamento de Dados (SERPRO), e que objetiva "a execução, com exclusividade, por processos eletromecânicos ou eletrônicos, de todos os serviços de processamento de dados e tratamento de informações, necessários aos órgãos do Ministério da Fazenda, a execução de serviços congêneres que venha a contratar com outros órgãos da Administração Federal, Estadual ou Municipal; a prestação do assessoramento técnico a êsses mesmos órgãos, no campo de sua especialidade".

Os resultados mais visíveis da atividade do SERPRO em relação aos contribuintes, dizem respeito ao cadastro de pessoas jurídicas, ao cadastro de pessoas físicas, ao cadastro de importadores habilitados, ao cadastro especial de contribuintes de tributos aduaneiros, ao cartão de identificação do contribuinte e ao documentário de arrecadação de tributos.

Atrás da atividade do SERPRO deve-se mencionar o cadastro realizado pelo ex-IBRA, em relação à propriedade territorial rural; e a aplicação de processamento de dados no Sistema Financeiro; no Sistema Nacional de Habitação; e nos planos de Integração Social e de Fundo de Garantia de Tempo de Serviço.

Os Estados seguiram o exemplo federal.

A Guanabara, em lei de dezembro de 1968 criou a Assessoria Geral do Sistema de Processamento de Dados, órgão integrante da Secretaria de Govêrno, normativo e coordenador dos sistemas de computação da administração direta e indireta daquele Estado.

A experiência do Govêrno carioca, além do uso de técnicas eletrônicas na administração geral, extravasou êsses limites, para outras atividades.

Entre essas, o registro de pessoas jurídicas e de pessoas físicas, contribuintes dos impostos sôbre circulação de mercadorias, sôbre serviços e territorial e predial urbano, compreen- 
dendo o grupo de impostos sôbre produção e circulação, 200 mil contribuintes; e sôbre patrimônio, 800 mil.

E um serviço contínuo de contrôle, que vai desde o cadastramento, acompanhando as fases de declaração, revisão, lançamento, notificação, pagamento ou atraso na liquidação da obrigação tributária, e desta, ao ingresso em juizo, em executivo fiscal e até final liquidação do débito.

Instituiu-se uma estratificação de variáveis e de parâmetros para observação da receita fiscal em relação à atividade do contribuinte, que permite detectar a evasão de tributos; e a ação de fiscalização é comandada pelo computador, saindo o fiscal a campo, com o auto de infração pràticamente lavrado, contra as firmas cujas declarações fiscais não coincidem com os índices de apuração eletrônica.

As multas de legislação de trânsito, conjugadas às fases de habilitação do motorista e de emplacamento de veículos, foram objeto de projeto já implantado.

Por igual, estão prontos os registros da Junta Comercial, abrangendo as anotações de constituição, alteração, fusão, incorporação e extinção do capital da pessoa jurídica, e aliadas aos registros de tributo e de participação societária, esta última, condição essencial para a repressão ao abuso do poder econômico que é de competência da União.

E ainda mais, os estudos sôbre identificação de pessoas, no Instituto Felix Pacheco, conduziram à transferência de problema para a área federal, sendo provável sua implementação em têrmos nacionais, em um sistema de mútuo apoio entre os organismos policiais da União e dos Estados.

Face ao trato dessas questões pela Guanabara, os governos dos Estados do Rio, do Espírito Santo e da Bahia foram levados a examinar as ditas soluções para igual procedimento.

Já São Paulo, seguindo trilha semelhante, criou a PRODESP (Cia. de Processamento de Dados do Estado de São Paulo); e em Goiás, estamos cientes de que os serviços de computação de interêsse estadual estão confiados aos órgãos CELG e CODEGO.

Seja-nos, nesta oportunidade, permitido discutir apenas um problema entre muitos, que, em breve, chegará à banca dos advogados: - O VALOR PROBANTE DO TRABALHO DO COMPUTADOR.

A prova legal é direta ou circunstancial. A direta é a testemunhal, de pessoas que viram ou sabem de fato, exceção 
dos legalmente impedidos ou dos que não podem ser testemunhas. Ou a prova documental, por escrito, seja um documento original, seja cópia autenticada do mesmo, e nesta categoria, incluído o laudo pericial. A circunstancial é hipotética. Deriva do processo de indução.

Por presunções, constrói-se um esbôço de solução considerando-se fatos, resultados experimentais e circunstanciais pessoais, até que, por eliminação, conclui-se quem seja o suspeito.

A hipótese contém especificações variáveis, e pelo confronto e por eliminação, tem-se um ou alguns suspeitos, na fase semifinal do caso.

A convergência leva, enfim, a um único suspeito, quando haja evidência conclusiva de culpabilidade.

Agora, voltemos ao computador.

Está em curso, no Ministério da Fazenda, um trabalho de levantamento de grupos de atividades econômicas, na faixa de fiscalização do Impôsto de Renda, para análise do comportamento fiscal de grupo de contribuintes. Processada uma escoIha de emprêsas de certa atividade econômica, com base na declaração de rendimentos, cujos dados principais estão perfurados pelo SERPRO, são as mesmas emprêsas analisadas, face a parâmetros estabelecidos, para seleção com o objetivo de fiscalização. O serviço se baseia, evidentemente, em amostragem estatística.

Daí, feita a listagem e indicados, pelo computador, os contribuintes selecionados, passa-se à fase de campo, sob responsabilidade do grupo ocupacional fisco.

Concluímos, pelo exposto, por considerar a escolha do computador como prova circunstancial de sonegação fiscal .

Comentávamos, em nosso livro Curso de Direito Financeiro Brasileiro, alguns aspectos da Lei no 4.729/65, que define os crimes de sonegação fiscal:

"Finalmente, cabe-nos dizer algumas palavras sôbre - lançamento ex-ofício do Impôsto de Renda. É um aditamento à renda declarada, com base na renda presumida, obtida através de certos parâmetros, cuja mensuração constitui os chamados sinais exteriores de riqueza". Baseia-se numa aproximação entre a renda dita auferida pelo contribuinte, e o que presumivelmente consome". 
E ainda:

"Parece-nos um sistema complementar de verificação fiscal, que é sempre por aproximação, e sujeito à inexatidão ou a avaliações subjetivas". (págs. 286/7).

Deixemos, quando na ocorrência de casos concretos, como será encarado, pela Justiça, o valor de prova circunstancial, obtida eletrônicamente.

Não vamos, aqui, comentar o conteúdo da primeira edição de nossa recente obra Direito e Cibernética.

Apenas, cabe dizer-se que a imprensa de todo o país dedicou alguns registros, e entre os colhidos, desejamos reproduzir os comentários seguintes:

O GLOBO, de 19 de outubro de 1970 , focalizou o problema do verdadeiro dilúvio legislativo, com as 110.000 leis e decretos federais em vigor, compondo o direito positivo brasileiro, e com graves conseqüências, inclusive, quanto à asfixia do processo do desenvolvimento econômico, por superposição de leis, em dispositivos conflitantes. Por conseguinte, disso resultou a entrevista ali contida, a propósito da possibilidade de utilização da técnica de computação eletrônica, para que dessa massa se extraísse o essencial, revogadas as normas em desuso $e$ as supérfluas.

O editorial de 1 \% de novembro do JORNAL DO BRASIL, sob o título o Primado da Lei, comentando a realização, em São Paulo, da IV Conferência Nacional da Ordem dos Advogados do Brasil, destacou:

"Na mesma sessão da Conferência, um professor da Universidade de Brasília verberou a morosidade da Justiça no Brasil, lembrando que o Tribunal Federal de Recursos, em agôsto último, julgou um processo iniciado em 1892".

O ESTADO DE SÃO PAULO, de 29 de outubro, sob o título "Advogados sugerem um nôvo currículo", inserindo o noticiário da IV Conferência Nacional da OAB, frisou:

"O professor Igor Tenório, da Universidade de Brasília, sustentou em carta que dirigiu ao Ministro da Justiça a conveniência de que seja feita uma simplificação do sistema jurídico brasileiro, alegando que existem atualmente no País 110 mil diplomas legais.

Segundo afirmou, isto é "um sintoma de fragilidade, que se reflete também nos tribunais, onde alguns processos dormem nas gavetas". 
"O professor Tenório defende a utilização de computadores para o aperfeiçoamento do processo legislativo, análise da jurisprudência, levantamento da legislação e até para informação de caráter jurídico."

A nota de elogiosas referências a Direito e Cibernética, da PROVÍNCIA DO PARÁ, de 28 de outubro, poderia ser somada a outras mais 50 publicações, saídas na imprensa do País, ou seja, em aproximadamente um quarto dos jornais diários do Brasil.

Cabe-nos, ainda, lembrar alguns tópicos de longa entrevista por nós concedida ao CORREIO BRAZILIENSE, de $11^{\circ}$ de novembro de 1970:

"A justiça não se realiza, se demora, se é cara ou se - acesso à mesma encontra óbices que a transformem em instrumento apenas à disposição dos mais favorecidos. A excessiva quantidade de leis sôbre o mesmo assunto gera confusão e incerteza, na aplicação do Direito. O anacronismo das leis processuais resulta no crescente acúmulo de processos. Para ilustrar, convém mencionar que a Guanabara conta, no momento, com cêrca de 300 mil processos judiciais em curso, muitos dos quais ainda se arrastarão, na marcha atual, até o final do século.

A demora nos julgamentos gera receio do apêlo ao Judiciário, e a feitura de leis, a técnica legislativa, vem sendo progressivamente descurada, havendo leis importantes não elaboradas, embora previstas no texto constitucional, e sobrando outras tantas, o mais das vêzes, repetições e alterações parciais das leis existentes.

Por fim o próprio ensino do Direito, apesar de tôdas inovações tentadas, não marchou para uma adequação entre a necessidade de formação de novos profissionais, dentro de um currículo compacto, em que se ensine o essencial, com o mesmo cunho prático já observado, por exemplo, no ensino das ciências médicas e na área de ciências exatas".

Doando os direitos autorais do livro já referido ao Movimento Brasileiro de Alfabetização (Mobral), e respondendo a uma indagação nesse sentido, dissemos, na citada entrevista, estas palavras:

"Assim, quis lembrar que lado a lado com a mais requintada tecnologia, o Brasil deve erradicar a man- 
cha do analfabetismo, que, para nossa geração, encerra o mesmo desafio já vivido por nossos avós, no século passado, durante as lutas em favor da abolição da escravatura.

A máquina deve redimir o homem. Porém, a tecnologia implica, para ser uma justa oportunidade no sentido de maior confôrto e de maior liberdade, que a degradante chaga do analfabetismo seja extirpada. Como professor estou plenamente convencido da sinceridade de propósitos do Ministro Jarbas Passarinho, e desejei, por isso, de público, levar-lhe uma modesta contribuição financeira, como estímulo a outras contribuições, e no sentido de apoio popular em favor de quem ataca o mais grave problema brasileiro.

0 analfabetismo degrada, chumba e impossibilita qualquer melhoria ulterior do homem. E sem o homem realizado em suas aspirações, o emprêgo da tecnologia conduz apenas à brutalização e ao apêlo à animalidade". 